\title{
When the going gets rough: effect of maternal size manipulation on larval quality
}

\author{
Dustin J. Marshall ${ }^{1,2, *}$, Michael J. Keough ${ }^{1}$ \\ ${ }^{1}$ Department of Zoology, The University of Melbourne, Victoria 3010, Australia \\ ${ }^{2}$ Present address: School of Biological, Environmental and Earth Sciences, University of New South Wales, \\ New South Wales 2052, Australia
}

\begin{abstract}
Variation in larval size has been shown to be an important factor for the post-metamorphic performance of marine invertebrates but, despite its importance, few sources of this variation have been identified. For a range of taxa, offspring size is positively correlated with maternal size but the reasons for this correlation remain unclear. We halved the size of colonies in the bryozoan Bugula neritina 1 wk prior to reproduction (but during embryogenesis) to determine if larval size is a fixed or plastic trait. We manipulated colonies in such a way that the ratio of feeding zooids to reproductive zooids was constant between treatment and control colonies. We found that manipulating colony size strongly affects larval size; halved colonies produced larvae that were $\sim 13 \%$ smaller than those produced by intact colonies. We entered these data into a simple model based on previous work to estimate the likely post-metamorphic consequences of this reduction in larval size. The model predicted that larvae that came from manipulated colonies would suffer $\sim 300 \%$ higher post-metamorphic mortality and $\sim 50 \%$ lower fecundity as adults. Colonies that are faced with a stress appear to be trading off current offspring fitness to maximize their own long-term fitness and this may explain previous observations of compensatory growth in colonial organisms. This study demonstrates that larval size is a surprisingly dynamic trait and strong links exist between the maternal phenotype and the fitness of the offspring. The performance of settling larvae may be determined not only by their larval experience but also by the experience of their mothers.
\end{abstract}

KEY WORDS: Offspring size $\cdot$ Maternal effect $\cdot$ Regeneration

Resale or republication not permitted without written consent of the publisher

\section{INTRODUCTION}

Most theoretical models of recruitment in benthic invertebrate populations assume that larvae settling into a population all have an equal chance of survival and success (Alexander \& Roughgarden 1996, Connolly \& Roughgarden 1998). This view changed with the discovery of carry-over effects; events that occur in larval life can affect the survival and performance of individuals as adults (Pechenik et al. 1998). We now recognize that settling larvae can vary greatly in their quality and potential for survival and growth. There are a number of sources of variation in larval quality. For example, extension of the larval period negatively affects post-metamorphic survival and growth in a number of marine invertebrates (Pechenik et al. 1998) and exposure of larvae to pollutants can also reduce their post-metamorphic performance (Pechenik et al. 2001, Ng \& Keough 2003). Variation in larval size has been shown to strongly affect post-metamorphic survival, growth and even reproduction (Moran \& Emlet 2001, Phillips 2002, Marshall \& Keough 2003a, Marshall et al. 2003). Variation in larval size may be a particularly important source of carry-over effects given 
the wide variation in larval sizes observed among and within populations (George 1994, 1999, Marshall \& Keough 2003b); yet despite its potential importance, sources of variation in larval size remain poorly understood. Although some factors have been demonstrated to affect offspring size in marine invertebrates (e.g. Cox \& Ward 2002), generalizations remain rare. One commonly cited source of variation in larval size is co-variation between larval size and maternal size.

In a wide range of taxa, larger mothers produce larger offspring (Sakai \& Harada 2001, Marshall \& Keough 2003b). Larval size may be a relatively fixed trait whereby larval size changes with maternal size due to changes in anatomical, physiological or nutritional constraints (Bernado 1996, Sakai \& Harada 2001). Larval size could also be a fixed genetic trait, which is correlated with high quality, larger mothers (Reznick 1981). Alternatively, larval size could be a plastic trait whereby mothers manipulate the size of their offspring to maximize their own fitness according to the local environmental conditions (Hendry et al. 2001). Distinguishing among these alternative explanations is crucial given the importance of larval size to the post-metamorphic performance of individuals. Offspring size often shows wide population level variation, but whether this variation reflects local adaptation of mothers to the local environment or simply reflects nutritional or genetic differences among populations remains unknown (George 1994, 1999, Bertram \& Strathmann 1998, Marshall et al. 2000). In order to discriminate among these explanations, experimental manipulations of maternal size that are independent of maternal age, genetics and nutrition are necessary.

Here we experimentally manipulate the size of mothers independently of potentially confounding variables such as genetics and age, and examine the consequences of that size manipulation for offspring in the marine bryozoan Bugula neritina. Previously we have shown that offspring size is strongly related to maternal or colony size in this species and furthermore, that larger larvae grow into larger colonies that in turn produce larger larvae themselves (Marshall et al. 2003). B. neritina, like all bryozoans, is a modular species, and colony size may be manipulated experimentally by removing portions of the colony without killing the whole organism. This allows the manipulation of maternal size independently of maternal age and nutritional state. B. neritina bears its young in specialized brood chambers known as ovicells. Whilst in these ovicells, offspring are provisioned through a specialized placenta-like system during embryogenesis (Woollacott \& Zimmer 1975). During this time, larvae increase in volume approximately 500-fold, and any change in maternal size has the potential to influence the provisioning of those offspring whilst it is being brooded. We manipulated colony size during embryogenesis. The colonies were manipulated so that colony size decreased but the ratio of feeding zooids per ovicell remained constant between treatments and therefore the nutritional state of colonies was unaltered. We found statistically significant differences in the size of larvae produced by manipulated and unmanipulated colonies and we were therefore interested if the observed differences were of biological significance. We used a simple model based on previous work at the same site (Marshall et al. 2003) to estimate the consequences of the observed differences in larval size for subsequent survival and fecundity of those offspring.

\section{MATERIALS AND METHODS}

We placed a large $(600 \times 400 \mathrm{~mm})$ grey perspex plate at a depth of $1.5 \mathrm{~m}$ below the low water mark at Breakwater pier, Williamstown, during November 2000. After about 2 wk in the field, we hauled the plate up and placed it into a shallow pool. Using a pair of fine forceps we then removed all the organisms that had settled on the plate other than Bugula neritina. We repeated this process after approximately 2 further weeks in the field but at this stage we also removed any very small $(<2$ bifurcations) $B$. neritina colonies, leaving a monoculture of relatively large $B$. neritina colonies distributed fairly equally over the whole plate. After about $5 \mathrm{wk}$ in the field, almost all the colonies had developed ovicells, but very few of these ovicells were occupied by fully developed larvae. After $6 \mathrm{wk}$, we divided the plate into a grid with twelve $200 \times$ $100 \mathrm{~mm}$ grid squares. Each grid square was then randomly allocated into either a treatment or control group and thus a grid square was the unit of replication. All the $B$. neritina colonies within the treatment grids were halved in size by cutting the colony just above the first bifurcation of the colony at its base. The $B$. neritina colonies within the control grids were left intact. After $1 \mathrm{wk}$, all the colonies were brought into the laboratory and maintained in lightproof, recirculating aquaria for $2 \mathrm{~d}$. The colonies were then carefully removed from the settlement plate using forceps and each colony was placed into its own 21 plastic container filled with seawater and exposed to bright light. The colonies began spawning almost immediately and after about 30 min we collected a small $(n=50)$ subsample of larvae from each colony. The larvae were then killed with a few drops of formalin and measured as in Marshall et al. (2003).

Survival probabilities for the larval sizes produced by colonies in the 2 treatments were back calculated from logistic regression equation where $B_{0}=-10.184$ and $\mathrm{B}_{1}=1.808$ from Marshall et al. (2003). Fecundity 
was calculated from the regression equation: no. of ovicells/ colony $=0.013 \times($ larval size $)-539$ (Marshall et al. 2003).

\section{RESULTS}

Colonies that had their size reduced had begun to regrow zooids on their damaged side, but no ovicells were visible in the re-grown portion $1 \mathrm{wk}$ afterwards. There was no significant difference in the ratio of feeding zooids to number of larvae released between halved and whole colonies $\left(F_{1,10}=1.66, \mathrm{p}=0.225\right)$.

Experimentally reducing the size of Bugula neritina colonies $1 \mathrm{wk}$ prior to collecting larvae affected the size of those larvae strongly $\left(F_{1,10}=9.59, \mathrm{p}=0.011\right)$. Interestingly, halved colonies also produced broods of larvae that were more variable in size ( $t$-test on withincolony coefficients of variation: $t=5.3, \mathrm{df}=10$, $\mathrm{p}<0.001$ ). Those halved colonies produced larvae that were, on average, $12 \%$ smaller than larvae from the control colonies (Fig. 1). This difference in larval size translates into a large difference in the survival as colonies beyond 4 wk (probability of survival 78 and $25 \%$ for larvae from intact and halved colonies, respectively). (values back calculated from logistic regression). Larvae that came from halved colonies would also have lower fecundity than those from whole colonies. The smaller larvae from manipulated colonies are predicted to produce $\sim 94$ ovicells as 6 wk old colonies whereas the larger larvae from unmanipulated colonies are predicted to produce $\sim 176$ ovicells as $6 \mathrm{wk}$ old colonies.

\section{DISCUSSION}

Experimentally reducing the size of Bugula neritina colonies $1 \mathrm{wk}$ prior to collecting larvae affected the size but not the per zooid number of larvae that were released. Colonies that were experimentally halved produced larvae that were much smaller in size than colonies that were not experimentally halved. It is important to note that although colony size was dramatically reduced, the amount of energy that was potentially available for the provisioning of offspring remained unchanged by the manipulation. The ratio of feeding zooids/colony biomass to ovicells was unaltered by the reduction in colony size. Consequently, we believe that any reduction in the size of larvae represents a shift in the allocation of resources from reproduction to elsewhere. A number of studies have shown that resources can be translocated from one part of the colony to the other (Miles et al. 1995) and it appears that in $B$. neritina, resources can be diverted from lar-

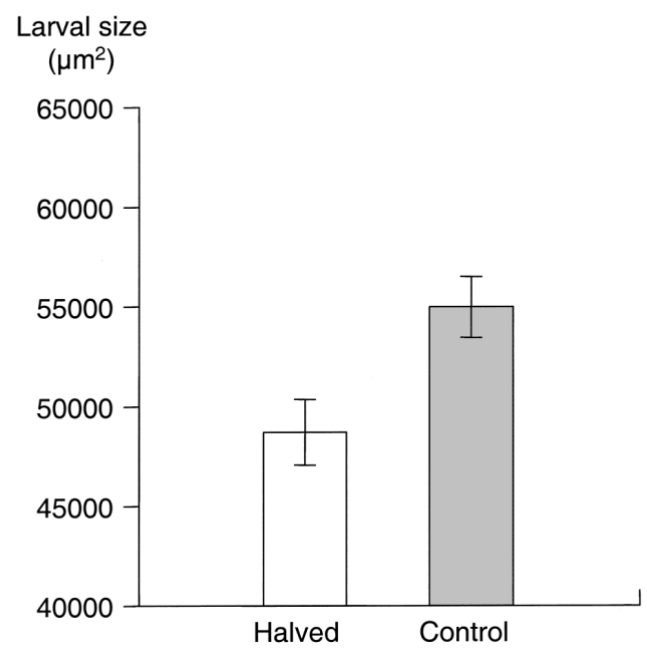

Fig. 1. Bugula neritina. Mean size of larvae produced by halved (open) and whole (shaded) colonies in the field at Williamstown, Australia

val provisioning to colony regeneration. An alternative explanation for our results is that the reduction in colony size reduced the overall feeding efficiency of the (now smaller) colonies and this resulted in smaller larvae. In B. stolonifera, Okamura (1984) showed that, in fast water flows, larger colonies feed more efficiently than smaller colonies. We believe this is not applicable in this instance, given that our experiment was conducted in the relatively slow flowing waters of a sheltered breakwater.

Colony size reduction not only resulted in a shift in the mean size of larvae that were produced, but in increased within-colony variation in larval size. Halved colonies produced larvae that were more variable in size than intact colonies. This may be a consequence of localized translocation of colony resources. During colony regeneration, reproductive zooids near the base of the colony may have had more resources removed than zooids near the top of the colony. Thus, larvae that were produced near the base of the halved colonies may have been much smaller than larvae near the top of the colonies. If the effects of regeneration on larval size are indeed relatively localized, this suggests that regeneration depends principally on the energy reserves of zooids adjacent to the damaged area ('localized regeneration hypothesis' in Oren et al. 2001). In contrast, Oren et al. (2001) suggest that colony regeneration depends on the entire colony rather than the local area. An appropriate test to distinguish between these explanations will be to examine (1) whether larval size varies from the colony base to the tip in damaged colonies, and (2) whether different sized colonies react to damage in the same way (e.g. Oren et al. 2001). 
The reduction in larval size associated with reduction in colony size is likely to have profound consequences for the fitness of the offspring. Our simple model showed that the smaller larvae produced by the halved colonies were 3 times more likely to suffer post-settlement mortality. Furthermore, colonies from smaller larvae (that come from halved colonies) are likely to have less than $50 \%$ of the fecundity of colonies from larger larvae. Larger larvae also remain choosier for longer than smaller larvae, and are more likely to settle into better microhabitats and therefore have higher survivorship (Keough \& Downes 1982, Walters \& Wethey 1996, Marshall \& Keough 2003c). Combining the likely effects of larval size on settlement, post-metamorphic survival and fecundity, it appears that colonies that had their size reduced produce offspring with far lower fitness than those produced by intact colonies. Size-reduced colonies may be trading off the fitness of their offspring to maximize their recovery from the size manipulation.

Trading off quality of offspring for colony growth probably maximizes current colony fitness, as colony size in colonial marine invertebrates has been shown to affect competitive interactions and the chances of surviving a predation event (Russ 1982, Sebens 1987). Bone \& Keough (unpubl. data) found that the removal of an entire branch from Bugula neritina colonies did not affect the subsequent growth of colonies. This is consistent with our observations; branch removal may have no effect on growth due to a redirection of resources from reproduction to growth. A number of other studies have demonstrated compensatory growth by colonial organisms after a reduction in colony size (e.g. Sanchez \& Lasker 2004). It appears that, for $B$. neritina, the resources for growth and reproduction are drawn from a common pool and can be reallocated by colonies when conditions change. Other studies have demonstrated that when allocating resources to reproduction, mothers trade off the fitness of their offspring to maximize their own fitness (Cunningham \& Russell 2000, Einum \& Fleming 2000). In $B$. neritina, mothers may be trading off current offspring fitness for future offspring (and hence colony) fitness.

In a range of colonial organisms, predation and physical disturbance can alter the size of colonies (Karlson 1986, Sebens 1987). The consequences of size reduction for colony survival and fecundity have long been recognized (Rinkevich 1996, Davis 1988). Our results demonstrate that disturbances that change colony size will not only affect the quantity of offspring that are produced, but also the quality. This represents a previously unforeseen consequence of colony disturbance/fragmentation events. It should be noted that the timing of the colony size manipulation may have affected our findings. We halved colonies when the fertilization of eggs had already occurred. It may be that larval number rather than size may change (Rinkevich 1996) if the size manipulation occurs prior to fertilization, but this remains to be tested. Interestingly, Hughes et al. (2003) found that when the bryozoan Celleporella hyalina was damaged, the production of female zooids (and thus number of larvae that will be brooded) was greatly reduced. Hughes et al. (2003) also found that colony damage resulted in an increased allocation to male function and they interpreted this as a reproductive 'bail-out'. An interesting challenge will be to examine how the timing of colony damage affects the size/number of offspring produced in $B$. neritina and the allocation to male and female function.

Larval size appears to be a plastic trait in Bugula neritina: when the maternal environment was experimentally manipulated, this resulted in the change in the phenotype (size) of larvae. Thus, it appears that in this species, the co-variation between maternal and larval size is an adaptive trait; despite being capable of producing smaller offspring, larger mothers are producing offspring of a much larger size (Bernado 1996). Parker \& Begon (1986) suggested that larger mothers produce larger offspring because of increased likelihood of sibling competition-larger mothers also tend to be more fecund and therefore each offspring requires more resources to deal with more competition. This may be occurring in B. neritina; larger larvae have a greater dispersal potential than smaller larvae and are therefore more likely to disperse away from the natal habitat (Marshall \& Keough 2003c). Regardless, larval size can clearly change according to local conditions and variation in larval size among populations may represent local adaptation in this species. Furthermore, larval size is likely to be highly variable among and within populations due to variation in local disturbance regimes and fragmentation rates (Linacre \& Keough 2003). Strong links between the larval stage and the adult stage have already been demonstrated (Marshall et al. 2003). This study shows that these links extend to the maternal adult stage with events in maternal generation likely to result in persistent effects in the subsequent generation. Thus, the performance of settlers/recruits may be determined not only by their larval experience (Pechenik et al. 1998) but also by the experience of their mothers.

Acknowledgements. We thank Richard Emlet and Maria Byrne for very helpful comments on earlier versions of this manuscript. We also wish to thank Keyne Monro and 2 anonymous reviewers whose insightful comments greatly improved the manuscript. 


\section{LITERATURE CITED}

Alexander SE, Roughgarden J (1996) Larval transport and population dynamics of intertidal barnacles - a coupled benthic/oceanic model. Ecol Monogr 66:259-275

Bernado J (1996) The particular maternal effect of propagule size, especially egg size: patterns, models, quality of evidence and interpretations. Am Zool 36:216-236

Bertram DF, Strathmann RR (1998) Effects of maternal and larval nutrition on growth and form of planktonic larvae. Ecology 79:315-327

Connolly SR, Roughgarden J (1998) A latitudinal gradient in northeast Pacific intertidal community structure-evidence for an oceanographically based synthesis of marine community theory. Am Nat 151:311-326

Cox EF, Ward S (2002) Impact of elevated ammonium on reproduction in 2 Hawaiian scleractinian corals with different life history patterns. Mar Pollut Bull 44:1230-1235

Cunningham EJA, Russell AF (2000) Egg investment is influenced by male attractiveness in the mallard. Nature 404 : $74-77$

Davis AR (1988) Colony regeneration following damage and size-dependent mortality on the Australian ascidian Podoclavella moluccensis Sluiter. J Exp Mar Biol Ecol 123: 269-285

Einum S, Fleming IA (2000) Highly fecund mothers sacrifice offspring survival to maximise fitness. Nature 405: 565-567

George SB (1994) Population differences in maternal size and offspring quality for Leptasterias epichlora (Brandt) (Echinodermata: Asteroidea). J Exp Mar Biol Ecol 175: 121-131

George SB (1999) Egg quality, larval growth and phenotypic plasticity in a forcipulate seastar. J Exp Mar Biol Ecol 237: 203-224

Hendry AP, Day T, Cooper AB (2001) Optimal size and number of propagules: Allowance for discrete stages and effects of maternal size on reproductive output and offspring fitness. Am Nat 157:387-407

Hughes RN, Manriquez PH, Bishop JDD, Burrows MT (2003) Stress promotes maleness in hermaphroditic modular animals. Proc Natl Acad Sci USA 100:10326-10330

Karlson RH (1986) Disturbance, colonial fragmentation, and size-dependent life-history variation in 2 coral reef cnidarians. Mar Ecol Prog Ser 28:245-249

Keough MJ, Downes BJ (1982) Recruitment of marine invertebrates: the role of active larval choices and early mortality. Oecologia 54:348-352

Linacre N, Keough MJ (2003) Demographic effects of fragmentation history in modular organisms: illustrated using the bryozoan Mucropetraliella ellerii (MacGillivray). Ecol Model 170:61-71

Marshall DJ, Keough MJ (2003a) Effects of settler size and density on early post-settlement survival of Ciona intestinalis in the field. Mar Ecol Prog Ser 259:139-144

Marshall DJ, Keough MJ (2003b) Sources of variation in larval quality for free-spawning marine invertebrates: egg size and the local sperm environment. Invert Reprod Dev 44:63-70

Marshall DJ, Keough MJ (2003c) Variation in the dispersal potential of non-feeding larvae: the desperate larva hypothesis and larval size. Mar Ecol Prog Ser 255:145-153

Editorial responsibility: Roger Hughes (Contributing Editor), Bangor, UK
Marshall DJ, Styan CA, Keough MJ (2000) Intraspecific covariation between egg and body size affects fertilisation kinetic in broadcast spawning marine invertebrates. Mar Ecol Prog Ser 195:305-309

Marshall DJ, Bolton TF, Keough MJ (2003) Offspring size affects the post-metamorphic performance of a colonial marine invertebrate. Ecology 84:3131-3137

Miles JS, Harvell CD, Griggs CM, Eisner S (1995) Resource translocation in a marine bryozoan: quantification and visualization of ${ }^{14} \mathrm{C}$ and ${ }^{35} \mathrm{~S}$. Mar Biol 122:439-445

Moran AL, Emlet RB (2001) Offspring size and performance in variable environments: field studies on a marine snail. Ecology 82:1597-1612

Ng TYT, Keough MJ (2003) Delayed effects of larval exposure to $\mathrm{Cu}$ in the bryozoan Watersipora subtorquata. Mar Ecol Prog Ser 257:77-85

Okamura B (1984) The effect of ambient flow velocity, colony size and upstream colonies on the feeding success of Bryozoa. I. Bugula stolonifera Ryland, and arbourescent species. J Exp Mar Biol Ecol 83:179-193

Oren U, Benayahu Y, Lubinevsky H, Loya Y (2001) Colony integration during regeneration in the stony coral Favia favus. Ecology 82:802-813

Parker GA, Begon M (1986) Optimal egg size and clutch size: effects of environment and maternal phenotype. Am Nat 128:573-592

Pechenik JA, Wendt DE, Jarrett JN (1998) Metamorphosis is not a new beginning. Bioscience 48:901-910

Pechenik JA, Gleason T, Daniels D, Champlin D (2001) Influence of larval exposure to salinity and cadmium stress on juvenile performance of 2 marine invertebrates (Capitella sp I and Crepidula fornicata). J Exp Mar Biol Ecol 264: 101-114

Phillips NE (2002) Effects of nutrition-mediated larval condition on juvenile performance in a marine mussel. Ecology 83:2562-2574

Resnick D (1981) 'Grandfather effects': The genetics of interpopulation differences in offspring size in the mosquito fish. Evolution 35:941-953

Rinkevich B (1996) Do reproduction and regeneration in damaged corals compete for energy allocation? Mar Ecol Prog Ser 143:297-302

Russ GR (1982) Overgrowth in a marine epifaunal community: competitive hierarchies and competitive networks. Oecologia 53:12-19

Sakai S, Harada Y (2001) Why do large mothers produce large offspring? Theory and a test. Am Nat 157:348-359

Sanchez JA, Lasker HA (2004) Do multi-branched colonial organisms exceed normal growth after partial mortality? Proc R Soc Lond (Suppl) 271: s117-s120

Sebens KP (1987) The ecology of indeterminate growth in animals. Ann Rev Ecol Syst 18:371-401

Walters LJ, Wethey DS (1996) Settlement and early postsettlement survival of sessile marine invertebrates on topographically complex surfaces-the importance of refuge dimensions and adult morphology. Mar Ecol Prog Ser 137: 161-171

Woollacott RM, Zimmer RL (1975) A simplified placenta-like system for the transport of extraembryonic nutrients during embryogenesis of Bugula neritina. J Morphol 147: $355-377$

Submitted: February 24, 2004; Accepted: March 25, 2004 Proofs received from author(s): April 27, 2004 